\title{
DESCENTRALIZAÇÃO FISCAL E GASTO PÚBLICO
}

\section{João Batista de Rezende}

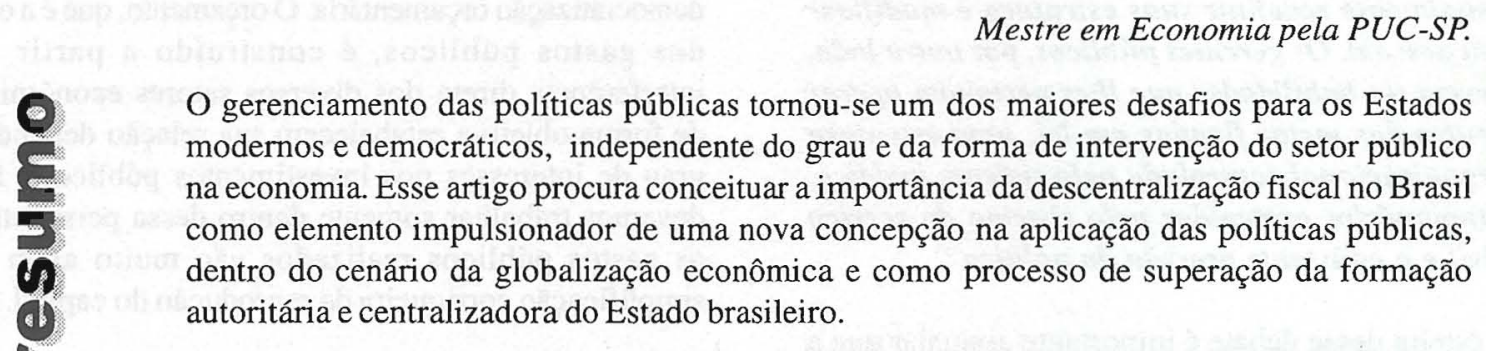

Palavras-chave: Brasil, Descentralização Fiscal, Gasto Público, Políticas Públicas, Estrutura Federativa, Reforma Tributária, Globalização.

\section{INTRODUÇÃO}

$\Delta$ tarefa principal desse artigo é mostrar a importância da descentralização fiscal, como ponto fundamental para a melhoria e eficiência dos gastos públicos. Eficiência que passou a ser crucial para os administradores públicos, pois mesmo com pequenos avanços, a sociedade civil tem exigido das esferas públicas (Governo Federal, Estados e Municípios) uma melhor definição na aplicação das políticas públicas.

Ao falarmos de descentralização fiscal teremos que correr os riscos inerente ao tema, visto que necessariamente discutiremos aspectos relacionados com a estrutura federativa brasileira ${ }^{1}$ (União, Estados e Municípios) e com o papel de cada uma destas esferas. Além disso, teremos que definir também alguns pontos básicos que possam discutir a questão da eficiência e melhoria dos gastos públicos.

Admitimos que este segundo ponto é, sem dúvida, o mais carregado de contradições. A visão da eficiência sempre esteve relacionada com a atividade privada e apenas mais recentemente a questão da eficiência na aplicação das políticas públicas apareceu nos debates acerca do setor

${ }^{1}$ CAMARGO, A. O Novo Pacto Federativo. In Revista do Serviço Público. Brasília, vol. 118. p. 87-94, n. ${ }^{\circ} 1$ jan.jul. 1994. público. Cabe colocar que não estamos nos referindo à eficiência largamente debatida na concepção neoliberal sobre a forma de atuação do Estado².

A análise de resultados passou a ser no campo da teoria econômica e social uma espécie de heresia. A construção teórica está relacionada invariavelmente com a super estrutura política, econômica e social, e ficou assentada basicamente na superação ou na manutenção do atual sistema de organização e produção econômica. A eficiência na aplicação das políticas públicas deveria ser vista como um elemento fundamental, independente da forma de se organizar para a produção.

E aqui entra um ponto de suma importância: a dificuldade maior para se buscar a qualidade na relação entre a aplicação das políticas públicas e seus resultados reside em uma compreensão bastante tosca da realidade acerca do setor público. As universidades brasileiras, por exemplo, só mais recentemente vêm promovendo cursos voltados para a administração pública. Cabe dizer que o administrador

\footnotetext{
2 Existe uma grande diferença entre a pregação da redução do papel do Estado, como produtor de bens e serviços, para o Estado que atua como regulador econômico e social. O avanço das formas de organização democrática tem exigido dos Estados nacionais uma intervenção ainda maior no processo de produção, mas agora não como produtor direto mas como instância de regulação econômica, social e política.
} 
público, independente de sua linhagem ideológica, deve ter mais informações e qualidades do que o administrador privado.

\begin{abstract}
"Em contraste com a educação para os negócios, por exemplo, o treinamento para a vida pública requer uma profunda compreensão do contexto político e constitucional da gestão governamental onde o poder e autoridade encontram-se amplamente difundidos. Enquanto ambos, a empresa privada e o Governo, demandam gerência eficiente, os instrumentos utilizados por um executivo de negócios são com freqüência as restrições nas quais o gerente público deve trabalhar. O executivo de negócios pode usualmente redefinir suas estrutura e modificar seu pessoal. Os gerentes públicos, por outro lado, devem ter habilidades que lhes permitam operar dentro das metas fixadas em lei, uma estrutura organizacional controlada pelo sistema jurídico, funcionários protegidos pelo sistema do serviço civil e a constante pressão da política"
\end{abstract}

Na esteira desse debate é importante assinalar que a perspectiva de discutir a eficiência no setor público só está sendo possível com os efeitos alcançados com a estabilização da economia, uma vez que a inflacão de forma objetiva escondia a ineficiência da máquina pública (inclusive e também das empresas privadas). O planejamento público era uma peça descartável. Por outro lado, é possível assinalar que a eficiência de nossos administradores públicos reside ainda nos resultados eleitorais, que são na maioria das vezes calcados no atendimento clientelista e pessoal.

Ao colocar em xeque estas formas de conceber as práticas de implementação das políticas públicas e de investimentos, não estamos nos referindo só a modelos gerenciais, mas é principalmente a forma de regulação do poder público, e isso fica mais visível quando trazemos esse debate para as esferas locais de poder. O controle na aplicação dos recursos públicos pode ter um caráter mais nítido quando debatido e discutido em nível local.

Os modelos centralizados de gestão pública, que vigoraram neste século, tornaram ineficiente a gestão das políticas públicas. São exemplos destes modelos centralizadores tanto o ex-bloco socialista (economia centralmente planificada), quanto o do capitalismo autoritário vivenciado nos países da América Latina, dentre eles o Brasil. Essas duas formas de regulação econômica acabaram por descartar um princípio fundamental, o controle público nas suas diversas fases do financiamento e da alocação dos recursos públicos.

É importante advertir que as colocações referentes à eficiência e melhoria nos gastos públicos estão diretamente

${ }^{3}$ KLIKSBERG, B. Uma gerência Pública para os Novos Tempos. In Revista do Serviço Público, Brasília vol.118. n. ${ }^{\circ}$, p.119, jan. jul. 1994. vinculadas a um aumento objetivo e material das condições de vida da população. Essas políticas vão desde os desdobramentos dos investimentos públicos nas áreas sociais até as questões referentes ao meio ambiente.

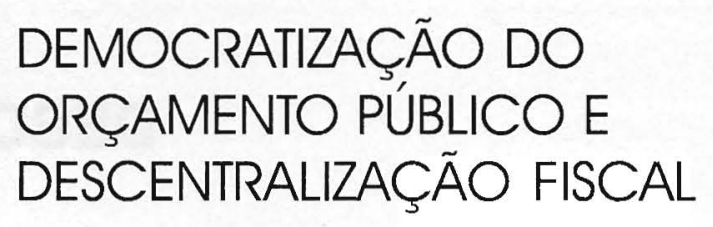

Um dos pontos recorrentes em torno do controle dos recursos públicos passa necessariamente pela democratização orçamentária. O orçamento, que é a expressão dos gastos públicos, é construído a partir de uma interferência direta dos diversos setores econômicos, que de forma objetiva estabelecem sua relação dependendo do grau de interesses nos investimentos públicos. ${ }^{4}$ Mas não devemos trabalhar somente dentro dessa perspectiva, pois os gastos públicos realizados vão muito além de uma simplificação corriqueira da reprodução do capital.

"A medicina socializada, a educação universal gratuita e obrigatória, a previdência social, o seguro-desemprego, os subsídios para transporte, os beneficios familiares (quotas para auxilio habitação, salário família) e, no extremo desse espectro, susídios para o lazer, favorecendo desde as classes médias até o assalariado de nível mais baixo...."

O controle do orçamento público passou a ser uma questão fundamental nos países industrializados. O controle público não só das políticas públicas de seguridade social, como da vigilância permanente aos gastos militares e os investimentos na proteção ao meio ambiente. Aqui entra um aspecto importante o Estado não é mais simplesmente um joguete na mãos da elite econômica, e sim um Estado que, sem comprometer as regras de acumulação do capital, procura de forma objetiva atentar-se para as pressões de outros segmentos sociais.

Ao largo dessas mudanças o Brasil ainda encontrase distante de uma formulação mais precisa em relação ao orçamento público. O caráter autoritário de formação do capitalismo brasileiro e o processo de condução econômica centrado na União, desde os primórdios de formação de nossa estrutura federativa, aliados ao intenso processo

\footnotetext{
${ }^{4}$ Uma análise importante a respeito da construção do orçamento público como expressão dos interesses particulares encontra-se desenvolvidas em:

O'CONNOR, J. USA: A Crise do Estado Capitalista. Rio de Janeiro, Paz e Terra, 1977.

5 OLIVEIRA, F. O Surgimento do Antivalor. In Novos estudos CEBRAP, São Paulo, n. ${ }^{\circ} 22$, P.8, Out. 1988.
} 
inflacionário na década de 80 , colocaram em segundo plano qualquer forma mais transparente e objetiva de construção do orçamento público.

Mesmo após a Constituição de 1988, as esferas locais de poder (municípios) ficam com apenas $23 \%$ da arrecadação nacional, contra $33 \%$ em média nas federações mais desenvolvidas. Somente na década de 90 , é que começam a aparecer as primeiras experiências em nível municipal de construção do orçamento público a partir de uma relação mais direta com a sociedade.

O primeiro ponto a ser definido nesse trabalho é o de conceituarmos e resolvermos a questão da descentralização fiscal que, inicialmente e para o propósito desse artigo, se refere ao conjunto de políticas públicas que teria como executoras, as esferas locais de poder ou o poder local. Tal pressuposto baseia-se na necessidade de que as demandas públicas (principalmente aquelas referentes às políticas públicas) sejam de interesse direto das comunidades locais.

Não queremos afirmar com isso que as demandas pelas políticas públicas, quando são colocadas sob a responsabilidade das esferas locais de poder, tenham caráter mais nítidos ou atinjam a população com mais equidade. Mas com certeza fazem melhorar a eficiência dos gastos públicos.

No seu artigo Governabilidade e Descentralização Dowbor, citando exemplo da Suécia, afirma que (...) $a$ descentralização dos recursos públicos constitui (...) um processo articulado com a evolução do funcionamento do Estado: quando $72 \%$ dos recursos financeiros do governo têm a decisão sobre o seu uso formulada no nível local de $\operatorname{poder}(\ldots)^{6}$

O fortalecimento das esferas locais de poder não pressupõe que todas as políticas a serem desenvolvidas pelas esferas públicas tenham como base as decisões em nível local, mesmo porque o Brasil com suas desigualdades regionais e distribuição espacial não homogênea ${ }^{7}$ requer políticas de alcance que vão além dos espaços regionalizados ou municipalizados.

Em outro extremo, as políticas públicas de interesse local não podem caoticamente ser decididas centralizadamente. Os fatos verificados quando da Comissão de Inquérito Parlamentar do Orçamento Federal ${ }^{8}$, em 1994, mostraram a fragilidade do nosso sistema de controle de verbas públicas no Brasil. E o fato mais importante é que, da totalidade das fraudes verificadas no orçamento, grande parte visava a atender demandas locais e, na maioria delas, de necessidade e prioridade duvidosas.

${ }^{6}$ DOWBOR, L. Governabilidade e Descentralização. In Revista do Serviço Público. Brasília, v.118, n. ${ }^{\circ}$ 1, p.108, Jan. Jul. 1994.

7 As desigualdades regionais fruto da concentração espacial dentro do desenvolvimento capitalista, encontra-se desenvolvida em:

OLIVEIRA, F. Elegia para uma Re(li)gião. Rio de Janeiro, Paz e Terra, 1981.

${ }^{8}$ A partir de 1995 houve algumas mudanças no orçamento público federal, principalmente no tocante às emendas individuais dos parlamentares; na tentativa de impedir novas fraudes, as emendas individualizadas foram limitadas.
Por outro lado podemos afirmar que a questão da descentralização fiscal não se resolve somente aumentando o poder decisório sobre as políticas públicas dos espaços locais. Mas também pela responsabilidade de financiar partes dessa descentralização, pois não estamos falando somente de descentralização de receitas ${ }^{9}$, o que ocorreu em grande medida na Constituição de 1988, em favor dos estados e municípios $^{10}$.

As esferas locais de poder devem também sair do imobilismo, pois exatamente por estarem próximas da sociedade civil descartam medidas de ajustes, ao pressupor acabar com o paternalismo e a renúncia fiscal. É necessário avançar na autonomia financeira, tanto em relação às políticas públicas como na geração de receitas.

É marcante, na tradição administrativa brasileira, a dependência dos municípios e mesmo dos estados dos recursos oriundos de outras esferas. A política de "pires na mão", conhecida nas décadas de 70 e 80 , quando prefeitos e governadores viviam a implorar recursos para suas localidades, ainda está longe de ser alterada em sua totalidade, apesar das transformações ocorridas no Capítulo Tributário na Constituição de 1988, onde aumentou-se a autonomia de estados e municípios em relação aos recursos financeiros.

Ainda hoje o alinhamento político por conta de recursos financeiros faz parte do nosso espectro partidário. São inúmeros os políticos que, uma vez eleitos para cargos executivos, tanto nos estados como nos municípios procuram alinhar-se aos ocupantes de cargos de esferas superiores. Assim, prefeitos procurarão alinhar-se a Governadores e estes, ao Presidente da República.

Este alinhamento raras vezes se dá por razões políticas; na maioria das vezes, representa uma tentativa de alocar mais recursos para suas administrações poupandoos da responsabilidade e obviamente dos desgastes de

9 Um dos aspectos mais importante da Constituição de 1988 foi promover uma descentralização de receitas em favor de estados e municípios. Os municípios elevaram sua participação de 14,27\% dos recursos efetivamente arrecadados no período $1964-1977$, para 22,75\% no período $1989-1990$.

BRITO MACHADO, H. Constituinte e Reforma Tributária. In Revista de Finanças Públicas, Brasília, n. ${ }^{\circ}$ 370, p. 45, abr/jun 1987.

${ }^{10}$ A Constituição de 1988 através do Capítulo Tributário promoveu uma elevação da participação dos estados e municípios na arrecadação tributária nacional, mas é preciso salientar que comparadamente com outros países, principalmente em relação aos municípios, (...) a média das federações desenvolvidas que não consideram os municípios entes federados a nível constitucional vamos encontrar aproximadamente $33 \%$ da carga tributária nacional destinados aos municípios (...) Ver:

MARTINS SILVA, I.G. Audiência Pública na Sexta reunião realizada em 29.4.87, na Subcomissão de Tributos Participação e Distribuição de Receitas. In Diário da Assembléia Nacional Constituinte, Brasília, p. 82, Jun. 1987. 
formular uma política geradora de receitas em nível local. ${ }^{11}$ Voltando ao nosso tema principal, a descentralização fiscal passa a ser um conjunto de medidas que redefina o papel de cada esfera pública (União, Estados e Municípios) tanto em relação à aplicação dos recursos como às fontes de financiamento. Entenda-se por isso um sistema baseado na inversão dos fluxos financeiros e que tenha como base o poder local.

As redefinições da forma de gerir os recursos públicos vão além dos aspectos gerenciais, o processo de gestão a partir das esferas locais de poder cria uma relação de responsabilidade do poder público para com a sociedade civil e vice-versa. A decisão local sobre os investimentos públicos passa a ser fundamental na condução e efetivação das prioridades demandadas.

Não trabalharemos pretensiosamente na busca do sistema ideal, mas partiremos da preocupação de que a consolidação política e o crescimento da cidadania vão além da roupagem atual da democracia representativa ${ }^{12}$. O surgimento e fortalecimento de organismos da sociedade civil, uma espécie de democracia direta ${ }^{13}$, foro do escopo institucional, discutindo e procurando soluções para os problemas locais, podem ser a base de uma nova forma de desenvolvimento.

Nessa década podemos relacionar uma série de iniciativas ligadas às esferas locais. Desde experiências do orçamento participativo desenvolvidos por algumas prefeituras, até a formação de consórcios intermunicipais que estão discutindo políticas de saúde, ecologia, turismo, políticas de desenvolvimento dentre outras, o que mostra uma certa superação do bairrismo político e administrativo.

Um segundo aspecto também importante é a própria conjuntura a analisar. $\mathrm{O}$ processo de centralização políticafinanceira, em quase todos os países da América Latina, cria dificuldades históricas para um processo de descentralização fiscal a curto prazo, e a complexidade dessas alterações é que, no Brasil, "as empresas estatais produtivas e os sistemas financeiros públicos são elementos de um conjunto de relações financeiras do setor público que passam a representar, ao lado de estruturas autônomas de financiamento, (...) uma parcela crescente dos gastos

${ }^{11}$ Nas nossas eleições municipais principalmente em cidades de menor porte, um dos fatores mais importantes para a avaliação política é se o candidato pertence ao mesmo partido do Governador ou do Presidente da República.

${ }^{12}$ São inúmeros os trabalhos sobre democracia com diversas perspectivas teóricas. Para o nosso artigo procuraremos apenas conceituá-las dentro de definições clássicas. A democracia representativa tem como base suas instituições públicas, legalmente reconhecida, dentro de normas previsíveis e sob o controle do Estado.

Ver:

GRUPPI, L. Tudo começou com Maquiavel.. Porto Alegre, Editora L\&PM, 1985.

${ }^{13}$ A democracia direta seria uma espécie de democracia participativa fora dos marcos institucionais. públicos ${ }^{\prime 14}$.

Isso faz com que muitos gastos realizados dentro das esferas públicas, principalmente em nível de Estados e União, passem a ser uma espécie de "carta branca" fora do controle público, (inclusive do sistema representativo legal), a exemplo do sistema previdenciário só incorporado ao Orçamento Geral da União após a Constituição de 1988.

\section{DESCENTRALIZAÇÃO FISCAL E GLOBALIZAÇÃO}

Além das dificuldades na implementação de uma profunda reforma fiscal, não poderíamos deixar de analisar a globalização econômica, ou seja, determinar qual é o papel dos Estados nacionais frente à economia mundial globalizada. Existe contradição entre uma profunda reforma fiscal e a política de globalização dos mercados mundiais?

Esses questionamentos tornam-se necessários em virtude de vários aspectos importantes. O primeiro deles está relacionado à função do Estado nas economias globalizadas. Há pelo menos uma vertente básica, embora não predominante, que tem como preocupação apenas a integração econômica de caráter liberal. Ou seja, a pregação da livre mobilidade de capitais e produção ou uma quase ausência do Estado.

Não há espaço na economia globalizada para "protecionismos", ou seja, sociedades autônomas, o processo tecnológico e de informação, a transnacionalidade financeira rompem com as barreiras e fronteiras. A reorganização do Estado passa por enfrentar a globalização de forma a garantir que suas políticas internas não sejam anuladas pela força dos mercados mundiais mas sim interaja com elas: (...) nos países desenvolvidos, a questão que se coloca já não é Estado versus não-Estado, e sim como refortalecer $o$ Estado sem suspender o processo de globalização ${ }^{15}$.

Esse aspecto é da maior importância, pois a descentralização fiscal aponta para dois caminhos. O primeiro leva o poder decisório dos investimentos públicos e principalmente o das políticas sociais públicas para as esferas locais de poder; o segundo é que a União pode concentrarse em políticas de médio e longo prazo, inclusive e prioritariamente em torno da inserção do país no cenário internacional.

A União ficaria assim com as grandes políticas, preocupando-se com os desequilíbrios regionais, com as

${ }^{14}$ PAULA, T.B. de - Centralização Fiscal e Políticas Públicas no Brasil. São Paulo. FUNDAP, P.5, Dez. 1989.

${ }^{15}$ FIORI, J.L. Globalização Estados Nacionais e Políticas Públicas. In Revista Ciência Hoje, Rio de Janeiro, vol. 16, n. ${ }^{\circ} 96$, p. 31 , dez. 1993.

${ }^{16}$ DAIN, S. Sistema Tributário Nacional. Mudanças Constitucionais/88. In Reforma Tributária possível e necessária, São Paulo, p. 100, Oboré, 1992. 
políticas macroeconômicas (câmbio, juros, preços públicos e dos setores oligopolizados), com as políticas de infraestrutura para o desenvolvimento nacional integrado (transportes, comunicações) e com as políticas de desenvolvimento tecnológico e industrial.

Quanto aos desequilíbrios regionais (...)num país de extrema desigualdade, como é o Brasil, tem que haver algum tipo de mecanismo equalizador para garantir um mínimo de igualdade $(. . .)^{16}$ Em relação às desigualdades sociais, a União deve atuar com os instrumentos clássicos tributários, utilizando-se da progressividade dos tributos principalmente aqueles incidentes sobre o patrimônio e as rendas mais elevadas ${ }^{17}$.

Com isso estaríamos desenvolvendo uma profunda reforma fiscal e ao mesmo tempo não descartando a globalização. Estaríamos criando as políticas compensatórias para fazer frente às consequiências das políticas de globalização dos mercados mundiais. Pois os riscos da globalização são evidentes, (...)pois fica extremamente difícil conceber e implementar uma política industrial (só para citar um exemplo ${ }^{18}$ sem ter mais o controle do risco (...) representado pela instabilidade crônica do câmbio e dos juros $(\ldots)^{19}$

Assim, ao mesmo tempo em que devemos aceitar a globalização do mercado mundial como inevitável, precisamos também reorganizar o Estado para que ele esteja apto a desenvolver políticas que observem as diversidades locais e utilizem instrumentos de regulação para desenvolver políticas compensatórias que minimizem os efeitos do processo de globalização da economia.

E diante do mercado mundial, (...)os instrumentos mais fundamentais são aqueles que manipulam os eixos macroeconômicos, a política cambial, a política monetária $(\ldots)^{20}$. É extremamente imperioso que o Estado crie condições de atuar na regulação dos instrumentos que tenham como variável sua interação com os movimentos financeiros e de produção no mercado mundial.

A questão da descentralização fiscal e a eficiência dos gastos públicos passam não só por uma profunda reforma fiscal, como pela evolução democrática da sociedade, sem mencionarmos a estrutura anacrônica de nosso sistema de representação política. Não poderíamos também deixar de trabalhar com o processo de globalização. Mas desde já afirmamos que não vemos contradição entre a formulação de uma política frente aos efeitos da globalização econômica e o processo de descentralização fiscal.

O fortalecimento das esferas locais de poder não significa a pregação de um Estado mínimo, mas apenas formas

${ }^{17}$ Ver:

SABÓIA, J. e ReIS CARVAlHO, J.C. A Progressividade do Sistema Tributário do Novo Texto Constitucional, Rio de Janeiro, mar. 1989. Mimeografado.

${ }^{18}$ Grifo nosso.

${ }^{19}$ FIORI, op, cit. p. 31.

${ }^{20}$ FURTADO, C. Entrevista. Novos Estudos Cebrap. São Paulo, n. ${ }^{\circ}$ 41, p. 107. Mar. 1995. diferentes de regulação e controle das políticas sociais públicas. Os temas aqui colocados tornaram-se importantes à medida em que os aspectos ideológicos de análise do comportamento do Estado e suas políticas passaram e vêm passando por profundas mudanças. Os novos paradigmas colocados aos administradores públicos aos partidos políticos e aos acadêmicos passam necessariamente por uma atitude propositiva, onde a formulação de novos conceitos de aplicação nas políticas públicas esteja ligada também aos seus resultados.

\section{REFERÊNCIAS BIBLIOGRÁFICAS}

AFONSO, C. A. e SOUZA H. O Estado e o Desenvolvimento Capitalista no Brasil. A Crise Fiscal, Rio de Janeiro, Paze Terra, 1977.

CAMARGO, A. O Novo Pacto Federativo. In Revista do Serviço Público, Brasília, vol. 118. n. ${ }^{\circ}$ 1, p. 87-94, jan.jul. 1994..

DAIN, S. Sistema Tributário Nacional. Mudanças Constitucionais/88. In Reforma tributária possível e necessária. São Paulo. Oboré, 1992.

DOWBOR, L. Governabilidade e Descentralização. In Revista do Serviço Público, Brasilia, vol. 118. n. ${ }^{\circ} 1$, p. 95-118, jan.jul. 1994..

FIORI, J.L. Globalização, Estados Nacionais e Políticas Públicas. In Revista Ciência Hoje, Rio de Janeiro, vol. 16. n. ${ }^{\circ}$ 96. p.24-31, Dez. 1993.

FUNDAÇÃO FARIA LIMA/CEPAM - Breves Anotações A Constituição de 1988, São Paulo, Atlas, 1990.

FUNDAP, Gasto Social: Estado e Setor Privado, São Paulo, IESP/FUNDAP, mar. 1991.

FURTADO, C. Entrevista. Novos Estudos Cebrap. São Paulo., n. ${ }^{\circ} 41$, p. $96-110$. Mar. 1995.

FURTADO, C. Globalização das estruturas econômicas e identidade nacional. In Estudos Avançados. São Paulo, USP, v. 6, n.16, p. 55-64, 1992.

KING, D. S. O Estado e as Estruturas Sociais de Bem-Estar em Democracias Industriais Avançadas. In Novos Estudos CEBRAP. São Paulo, n. ${ }^{\circ} 22$, p.53-76, Out. 1988.

KLISKSBERG, B. Uma Gerência Pública para os Novos Tempos. In Revista do Serviço Público. Vol. 118. n. ${ }^{\circ} 118$, p. 119-142, jan.jul. 1994. 
LONGO, C.A. A Disputa pela receita tributária no Brasil, São Paulo, IPE/USP, 1984.

NOGUEIRA, M.A. Permanência e Mudança no Setor Público. In Revista do Serviço Público. Brasília, Vol. 118. n. ${ }^{\circ}, 118$ janeiro/julho 1994, p. 43-54.

O'CONNOR, J. USA: A Crise do Estado Capitalista, Rio de Janeiro, Paz e Terra, 1977.

OLIVEIRA, F. O Surgimento do Antivalor. In Novos Estudos CEBRAP, São Paulo, Out. 1988.

OLIVEIRA, F. Elegia para uma Re(li)gião. Rio de Janeiro, Paz e Terra, 1981.

OLIVEIRA FABRÍCIO. A, A Reforma Tributária de 1966 e a Acumulação de Capital no Brasil, Belo Horizonte, Oficina de Livros, 1991.

PAULA, T.B. Centralização Fiscal e Políticas Públicas no Brasil, São Paulo, IESP/FUNDAP, dez. 1989.

SABÓIA, J. e REIS CARVALHO, J.C. A Progressividade do Sistema Tributário do Novo Texto Constitucional, Rio de Janeiro, Mimeografado. mar. 1989. 